\title{
Large animal models for stem cell therapy
}

\author{
John Harding', R Michael Roberts² and Oleg Mirochnitchenko*1
}

\begin{abstract}
The field of regenerative medicine is approaching translation to clinical practice, and significant safety concerns and knowledge gaps have become clear as clinical practitioners are considering the potential risks and benefits of cellbased therapy. It is necessary to understand the full spectrum of stem cell actions and preclinical evidence for safety and therapeutic efficacy. The role of animal models for gaining this information has increased substantially. There is an urgent need for novel animal models to expand the range of current studies, most of which have been conducted in rodents. Extant models are providing important information but have limitations for a variety of disease categories and can have different size and physiology relative to humans. These differences can preclude the ability to reproduce the results of animal-based preclinical studies in human trials. Larger animal species, such as rabbits, dogs, pigs, sheep, goats, and non-human primates, are better predictors of responses in humans than are rodents, but in each case it will be necessary to choose the best model for a specific application. There is a wide spectrum of potential stem cell-based products that can be used for regenerative medicine, including embryonic and induced pluripotent stem cells, somatic stem cells, and differentiated cellular progeny. The state of knowledge and availability of these cells from large animals vary among species. In most cases, significant effort is required for establishing and characterizing cell lines, comparing behavior to human analogs, and testing potential applications. Stem cell-based therapies present significant safety challenges, which cannot be addressed by traditional procedures and require the development of new protocols and test systems, for which the rigorous use of larger animal species more closely resembling human behavior will be required. In this article, we discuss the current status and challenges of and several major directions for the future development of large animal models to facilitate advances in stem cell-based regenerative medicine.
\end{abstract}

\section{Introduction}

The revolution in stem cell biology, begun in the early '80s with the isolation of mouse embryonic stem cells, has opened up the tantalizing possibility of wide-spread therapeutic interventions in humans. Various types of pluripotent or multipotent cells can potentially be used for preclinical or clinical investigations, including embryonic stem cells (ESCs), isolated from the inner cell mass of blastocysts; stem cells isolated from adult tissues; induced pluripotent stem cells (iPSCs), which are adult cells reprogrammed to pluripotency; and a variety of specialized cells obtained by differentiation from the above cell sources among others. The absence of animal models fully reflecting the target diseases to be investigated by using stem cells has prompted some investigators to attempt to bypass traditional preclinical

*Correspondence: oleg.mirochnitchenko@nih.gov

'Division of Comparative Medicine/ORIP/DPCPSI/OD, National Institutes of Health, 6701 Democracy Boulevard, Suite 943/950, Bethesda, MD 20892, USA

Full list of author information is available at the end of the article animal testing when developing stem cell therapies for humans. However, such approaches can cause significant damage to patients, ineffective and expensive treatments, and a negative effect on the future of the practice of regenerative medicine. The evolutionary conservation of stem cell function and homeostasis between humans and other mammalian species has facilitated the current progress in understanding the behavior of stem cells. It is also clear that certain aspects of stem cell biology are species-specific. Significant effort should be devoted to understanding these differences, which will facilitate use of the most appropriate model system for a given preclinical study. Further progress requires studies in a variety of model organisms as sources of stem cells and as hosts for allogeneic and xenogeneic tissue grafts to establish proof-of-principle and test the safety of potential therapies. The success of therapeutic approaches based on stem cells will require an improvement of animal disease models recapitulating human phenotypes, including the use of animals that have organs comparable in size and physiology to those of humans. Animal stem cells also provide new tools to generate genetically modified and humanized animals as better models for 
human conditions. The purpose of this article is to provide a brief overview of the use of large mammalian species that can bridge the gap between rodent models and humans to accelerate the translation of stem cell technology to clinical practice.

\section{Advantages and current limitation of the use of large animals as models for stem cell research and regenerative medicine}

Mice have been a species of choice to study stem cell biology in mammals. They are relatively inexpensive, reproduce quickly, and can be easily manipulated genetically. However, the ability of mouse experiments to predict the effectiveness of stem cell-based therapy remains controversial. The failure of many mouse models to precisely recapitulate particular human disease phenotypes has compelled investigators to examine animal species that may be more predictive of humans. Larger animals, such as rabbits, dogs, pigs, goats, sheep, and non-human primates, are often better models than mice for this purpose. They have a longer life span, which facilitates longitudinal studies critical for most stem cell applications. Many physiological parameters (for example, immune system properties that play an important role in the reaction of the host animal to cell transplantation) are much closer to humans than are those of rodents. Large animals also have significant advantages regarding the number and types of stem cells that can be reproducibly extracted from a single animal and manipulated in sufficient quantity for analysis and for various applications.

Large animal species can provide significant advantages when modeling specific human disease conditions and testing stem cell therapies. The following are several examples. Non-human primates and humans have very similar central nervous systems. Non-human primates can recapitulate human pathology and behavior in experimental models of a variety of neurological diseases, making them the most suitable species for testing stem cell therapies for brain diseases [1]. Several issues in the use of monkeys, such as the cost of husbandry and the specialized care that can be required for long-term monitoring, should be considered. Along with cat, dog, and non-human primate models, pigs are becoming very attractive as models to test stem cells for treating spinal cord injury. Advances in experimental surgery allow the creation of consistent and predictable deficits after calibrated spinal trauma very similar to human pathology. Another advantage is the ability to use equipment and techniques developed for human applications for cell delivery and monitoring of the animal. Serious limitations in understanding the specifics of spinal cord injury and recovery were discovered recently in rat models [2] Clearly, interpretation of the results of intervention and attempts to extrapolate the conclusions to human trials will be extremely difficult if based solely on experiments in the rat model. Another example of limitations of rodent models relates to attempts to test stem cell therapies for retinal degeneration. The mouse retina does not have a macula and it is rod-dominant and anatomically different from that of humans. Therefore, the pig is the more preferable species to use as a model for this particular application [3]. Advantages of using large animal species to model several other human disease conditions have been reported $[4,5]$.

Large animal species have a significant role in establishing the safety of stem cell applications, since the dosages of biologics, the route of administration, and treatment outcomes can be extrapolated readily to humans. The same is true for the development of procedures and techniques, such as surgical and visualization technologies, which will assist stem cell applications in the clinic. Non-invasive monitoring is required to guide cell injection; to observe cell survival, activation, and differentiation; and to evaluate off-target effects, cell persistence, and efficacy of engraftment. This information can be obtained by advanced anatomical and functional imaging techniques that will improve therapy in animal models, leading to clinical applications. Imaging technology and equipment, such as the micro-PET imaging system that provides high sensitivity and spatial resolution, have been developed for small animals. This and similar technologies can be applied to large animals and humans, although modifications and improvements will be required. Current progress and available imaging techniques for use in dogs, pigs, sheep, goats, and nonhuman primates were recently reviewed [6,7].

Research studies support the importance of the use of scaffolds and other homing devices that will instruct and control stem cell behavior. These devices should have the appropriate size and should be developed and tested in an environment suitable for clinical applications, for which large animals are a better choice than rodents. Large animals also allow a more realistic set of estimates of the quality and cost-effectiveness of new treatments.

Among limitations of the use of large animal species for regenerative medicine are a relative absence of stable and well-characterized stem cell lines and protocols for their maintenance, differentiation and monitoring of cell status, and limited availability of species-specific antibodies, expression microarrays, and other research reagents. Techniques to genetically manipulate these species are still in an early stage of development.

\section{Stem cells from large animal species}

Attempts to create ESCs from swine, cattle, and sheep were initiated not long after mouse ESCs were isolated [8]. Most importantly, mouse ESCs are readily incorporated into the inner cell mass of the blastocyst, with the 
genetic change to be examined in subsequent generations. A major impetus for producing ESCs from farm species was the possibility of conducting similarly targeted studies in a large animal, with the goal of improving animal health and productivity. Although cell lines originating from the inner cell mass or from embryonic germ cells have been described [8], it is clear that most do not meet the criteria for pluripotency shown by their mouse counterparts. The subsequent derivation of ESCs from primates, which had different culture requirements and colony morphologies than mouse ESCs, did not improve matters significantly. Indeed, only a few recent reports using swine have been sufficiently encouraging to believe that the barrier to generating pluripotent ESC lines from large animals has been overcome [9].

Genetic modification in swine for biomedical research has proceeded quite rapidly over the last decade $[10,11]$. Genetically modified pigs will be particularly useful for studying the pathophysiology of diseases, such as cystic fibrosis [12], in which mice fail to develop the relevant symptoms encountered in human patients, and retinitis pigmentosa [13], in which the anatomy of the pig eye is quite similar to that of the human. Genetically modified swine are also being developed as a potential source of tissues and organs for xenotransplantation into humans by minimizing hyperacute rejection through genetic modification [14]. However, in none of these examples were ESCs used to engineer any of the targeted modifications. Instead, the mutational change was performed in somatic cells, usually fibroblasts derived from embryos. Such cells have the ability to continue dividing long enough to allow limited selection of clonal colonies where homologous recombination has occurred, but they are not pluripotent and cannot contribute to chimeras and hence cannot be employed to generate chimeric offspring. Instead, the modified genome is propagated by somatic cell nuclear transfer (SCNT), the same cloning technology employed to create Dolly the sheep. Although this technology is still not an efficient process and often results in birth defects, it does enable offspring carrying the genetic change in one allele of the targeted gene to be created in the F1 generation. However, pluripotent cells might still have advantages over somatic cells for SCNT. Their long life span could, for example, enable multiple genetic changes of greater complexity to be introduced, and their 'undifferentiated' state may allow greater efficiency of reprogramming in the oocyte cytoplasm, a major limitation of the SCNT technology. Such possibilities have yet to be tested.

As an alternative to ESCs, iPSCs have been generated from pigs and other agriculturally important ungulates [15]. Various combinations of reprogramming genes in a variety of vectors have been employed. With a few exceptions, most of the resulting lines resemble human
ESCs, which are dependent on basic fibroblast growth factor and Activin/Nodal signaling to maintain their pluripotency. Such pluripotent lines are called prime- or epiblast-type and are characterized by flattened colony morphology, relative intolerance to passage as single cells, and inactivation of one of the X-chromosomes in female lines. They are often presumed to represent a 'more differentiated phenotype' than that represented by the so-called naïve cells, which arise when mouse somatic cells are reprogrammed. The latter, like the 'true' ESCs generated from outgrowths of the inner cell mass of mouse blastocysts, are dependent on LIF/STAT3 (leukemia inhibitory factor/signal transducer and activator of transcription 3) signaling, divide more rapidly than prime-type cells, and can be readily propagated from dispersed single cells. However, it has proved possible to generate such LIF/STAT3-dependent iPSCs from swine by applying selective growth procedures immediately following reprogramming [8].

What then is the value of iPSCs from a large animal like the pig? The possibility that they might be more useful than somatic cells for genetic modification and SCNT was discussed above. But perhaps their greatest potential will be in regenerative medicine. For example, if the cell types contemplated for future human use are considered to constitute a risk for cancer, analogous porcine cell grafts might first be tested in pigs, whose immune system is more similar to that of humans than is that of rodents. Large animal models will also be needed to perfect the surgical techniques needed to introduce stem cell derivatives into organs and tissues and to assess whether functional grafts form. Many of these procedures could be performed with autologous grafts, since it should be possible to generate iPSCs from piglets soon after they are born and to employ derivatives of these cells to establish grafts in the same animal from which they were derived. Thus, the pig and other large animals, because of their close anatomical and physiological similarities to the human, will find new roles in regenerative medicine.

\section{Chimeric animals and xenotransplantation}

Human autologous and allogeneic stem cells and their derivatives hold promise for regenerative medicine. The prediction of potential effects of transplanted cells is a significant challenge, taking into account the complex interactions of stem cells with different organs and the requirement of the cellular and molecular microenvironment for proper regulation, maintenance, proliferation, and biological function. One of the major obstacles for preclinical studies using human cells in animal hosts is the host-graft reaction, which can mitigate the beneficial effect and complicate the interpretation of results. Several approaches are currently used to overcome reactions in model organisms, including immunosuppression of the 
host animal, the use of genetically engineered animals that are immunodeficient or do not react to the transplanted cells, alterations in the stem cells, which affect their ability to induce immune responses, and other approaches.

An additional method, which has potential not only in the study of the plasticity of stem cells, immune tolerance, and stem cell differentiation but also as a model for prenatal treatment of disease, is based on the immune incompetence of the developing organism. This involves injection of human stem cells into the developing fetuses of large animal species.

A variety of human stem cell types - including bone marrow-, umbilical cord-, and fetal liver-derived hematopoietic stem cells, mesenchymal stem cells (MSCs), renal adult stem cells, and neural stem cells - have been used for this purpose [16] Cell expansion, long-term persistence, and multiple organ engraftment of human cells in live-born recipients were reported in rabbits [17], dogs, pigs [18], sheep [19], goats [20], and monkeys [21]. Procedures were optimized to maximize cell survival and tissue targeting using specific cell populations. Results of the studies revealed advantages and shortcomings of the use of the large animals. The benefits are that fetal development is much closer to that of humans. The gestation period allows long-term studies as well as similar sample collection for analysis. Monitoring procedures are also adequate for human fetal testing of growth and development, delivery techniques can be developed and tested, and the dosage and route of administration can be optimized. Among limitations are some differences in pregnancy and fetal development in large animals such as sheep, pigs, and goats relative to humans as well as the inability to use high-throughput approaches for screening and the absence of the methodology for easy genetic modification of the host.

Xenotransplantation between animal species was explored to study immune tolerance, molecular and physiological compatibility, risk of carryover infection, and other safety issues. These studies also provided model systems for the potential use of animal stem cell products in humans. A majority of reports focus on cell products from pigs as the most likely sources of cells for transplantation into humans. For example, fetal porcine neuroblasts were systematically rejected after intracerebral administration for the treatment of neurodegenerative diseases in other animal hosts, especially non-human primates [22]. Immunosuppression was required and produced secondary effects. In contrast, xenogeneic MSCs or expanded neuronal precursors show long-term survival and negligible immune reaction in immunocompetent animals [1]. Pig neuronal adult stem cells can be expanded easily, have immunosuppressive properties, and are able to generate all three neural lineages.
Additional protection for these cells can be provided by using genetically modified animals (for example, $\alpha$ galactosyltransferase knockout pigs expressing human complement regulatory genes or additional immunosuppressive genes or both) [23].

Overall, the nature of the immune response after xenogeneic MSC transplantation in animal models is not known definitively. A number of studies using rodent MSCs for allotransplantation [24] as well as other animal MSCs in rodents reveal immune response in immunocompetent animals. A smaller number of reports have indicated significant immune response in large animal species, including pigs and baboons $[25,26]$. In the latter case, large, multiple dosages were used and there was no correlation between MSC survival and the production of alloantibodies. Several explanations can be made for these discrepancies between reports and animal species, including the purity of the cell preparations, the organ of origin of the cells, and the extent of cell characterization in a given experiment and other experimental conditions or their combination. Intrinsic differences in the properties of MSCs between different species may also contribute to the variability of the results. For example, it was reported that mouse MSCs, despite having immunosuppressive properties in vitro, are much weaker in this regard than human MSCs [27]. Clearly, further studies in larger animals, especially non-human primates, are required to ensure patient safety in clinical trials using MSCs. A recent meta-analysis of large animal studies using MSCs indicates that in 88 of 94 reports, good cell engraftment and functional activity across the species barrier were obtained [28]. The vast majority of studies reported good cell engraftment and functional activity across the species barrier. Very few reports indicated complications, such as fibrous tissue in the liver or significant inflammatory responses. Owing to the significant number and purity of cells that can be obtained, adipose tissue has become the preferred source of MSCs in these animals. To ensure that such cells are safe to use in clinical practice, additional studies on cell survival, efficient suppression of the immune response, and any adverse effects should be conducted.

\section{Testing stem cell therapies for specific disease conditions using larger animal models}

Stem cell applications provide potential opportunities for therapy of a wide variety of human acute and chronic conditions for which there are no efficient surgical or pharmacological treatments. The choice of the most suitable disease condition as a target for intervention is determined by many factors, including the availability of reproducible and predictable model systems providing measurable outcomes that can be applied to human trials. Owing to the large number of diseases for which 
stem cell therapies are currently applied in animal models and the limited space in a short review article, we discuss here selected examples of testing this approach for diseases affecting different organ systems in large animal species. These were chosen on the basis of successful preliminary results, demonstrating advantages of using large animals and suggesting that such studies eventually will provide the safety and efficacy data required for clinical trials. In the majority of cases, these applications were first examined in rodents as a proof-of-principle and moved to larger animals for validation and eventual translation to the clinic.

\section{Ocular diseases}

Stem cell therapy has attracted significant attention for the treatment of irreversible blinding pathologies, such as retinitis pigmentosa and macular degeneration, and has already resulted in clinical trials. Recent studies have shown that many of the results obtained using stem cell grafting in rodents are reproducible in larger mammalian species, including the cat, dog, and pig [3]. Evidence has shown that retinal integration was substantial for transplanted cells but that photoreceptor differentiation was limited. A recent meta-analysis of the xenogeneic transplantation of human adipose-derived MSCs showed significant improvement in rabbits and dogs that received treatment for retinal injury [29]. Human bone marrow MSCs and immature dental pulp stem cells have been successfully used for ocular reconstruction in the chemical burn injury rabbit model [30]. Recently, iPSCs were derived from fetal pig fibroblasts as a source of rod photoreceptor lineage cells. These cells were able to differentiate into photoreceptors, integrate into the retina, and generate outer segment-like projections [31].

\section{Neuronal diseases}

There is significant enthusiasm for the use of neural stem cells for therapy of brain and spinal cord injury and neurodegenerative disorders. Non-human primates that receive 1-methyl-4-phenyl-1,2,3,6-tetrahydropyridine (MPTP) develop disease mimicking the sporadic forms of Parkinson's disease, including resting tremor, frontalstriatal cognitive deficits, and autonomic disturbances, which are not features of the widely used rodent models. Non-human primates are also an optimal model for preclinical evaluation using technologies requiring intracerebral targeting. In clinical settings, the accuracy of the delivery method significantly affects the efficacy of the therapy and should be tested in relevant animal models. Owing to the highly inbred nature of rodents often used in studies of Parkinson's disease therapy, stereotaxic brain atlases can be relied upon for delivery of the cells, a practice which is not suitable for human cases. Nonhuman primate anatomical variations and brain complexity are much more similar to those of humans and therefore are providing a more reliable set of preclinical data [32]. Allotransplantation of fetal monkey dopaminergic stem cells or ESC-derived dopaminergic neurons was successful and led to studies using human neural and adult stem cells introduced into monkeys. These cells survived in MPTP-treated animals and produced behavioral improvement [33,34]. Human neuronal precursor cells alone or cells overexpressing glial cell line-derived neurotrophic factor or insulin-like growth factor induced behavioral improvement, cell survival, and migration [35,36]. Use of dopamine neurons differentiated from human ESCs resulted in very limited cell survival, whereas allographic transplantation produced a better outcome [37]. Recently, excellent neuronal survival and function of human pluripotent and embryoderived dopamine neurons in the monkey model have been reported, testing the scalability of the approach toward use in the clinic [38,39]. A significant advantage of the use of large, long-lived animals is the ability to have a longer observation time for possible side effects as well as therapeutic benefits. The use of non-human primates also permitted the evaluation of the potential for reconstruction of the full dopaminergic pathway by cografting fetal tissue or growth factors into the striatum and substantia nigra at distances similar to those in the human brain [40]. Despite these advances in animal models, human trials so far have shown very modest and variable improvement, indicating that further optimization of techniques is required to improve efficacy before clinical use.

Investigations of the therapeutic effects of a variety of stem cell types for treatment of stroke, most commonly conducted in rodent models, demonstrated functional improvement and positive outcomes. However, proliferation or neuralization of the transplanted cells was not shown in most studies [1]. Survival of newly generated neurons, even when reported, was short-lived. There are significant differences in vascular, sensory, and motor systems in the brain of rodents and humans. Furthermore, rodents spontaneously resolve most of the dysfunctions caused by current procedures within several weeks. Therefore, demonstration of treatment efficacy in non-human primates would provide greater confidence for clinical trials. The use of these animals should address practical questions about cell types and dosage, the viability of particular routes of administration and therapeutic windows, postoperative care, the use of optimal approaches to follow the fate of transplanted cells, and long-term observation under conditions mimicking clinical applications. Relatively few studies have been carried out using non-human primates and stroke models. Recently, Sasaki and colleagues [41] created an improved model for stroke by using infusion of human 
MSCs into the African green monkey. The procedure was safe, and a trend toward functional improvement was observed. The investigators made an important observation that might influence the interpretation of future studies and will likely be observed in clinical trials because of the outbred nature of the population and the anatomical brain peculiarity of primates: variation in collateral circulation between individual animals even with similar lesions significantly affected the outcome. These experiments suggest that neuroprotection can be achieved by using current types of stem cell treatments. However, significant efforts should be directed toward improving approaches targeting proliferation, replacement, and integration of neuronal cells in large animal models before moving to human preclinical studies.

\section{Musculoskeletal diseases}

Stem cell therapies for the treatment of musculoskeletal tissue pathologies include transplantation of tissueforming cells, application of bioactive matrix materials, and delivery of bioactive molecules to sites of injury and repair. As for a number of other disease conditions, rodent models have been used widely for proof-ofconcept studies of osteoarthritis. However, thin cartilage, inadequate size and volume of the defects, intrinsic healing of the rodent models, and the inability to conduct long-term studies make rodents less useful than larger animal models for preclinical studies. Successful treatment of osteoarthritis in dogs, goats, and sheep has been reported using bone marrow- and adipose-derived MSCs [42]. Autologous MSCs were used with positive results in dogs and rabbits for the treatment of experimentally induced chondral defects and bone regeneration. Minipigs and horses are currently considered the most promising models for future studies (reviewed in [43]). Overall, despite the positive effects, the osteogenic potential was not consistent, suggesting that enriching the pure osteogenic population of MSCs before application may be beneficial.

Therapy for skeletal loss was tested in golden retriever muscular dystrophy dogs, one of the best models of the human disease. Clinical features of the Duchenne muscular dystrophy phenotype in dogs are more severe than in mdx mice. Dogs are therefore more predictive for characterizing the disease and for testing treatments. Human and canine umbilical MSCs were safe and engrafted well but did not differentiate into muscle cells, whereas human adipose-derived MSCs were able to engraft and express human dystrophin in the host muscle for a prolonged time (up to 6 months) and were healthy after 3 to 4 years of observation [44]. Studies using the dog model also indicated that multiple injections with intervals of up to 6 months may be required to maintain the proper level of exogenous dystrophin.

\section{Cardiovascular diseases}

Most of the information regarding cardiovascular biology has been generated using rodents. However, there are significant differences between cardiac characteristics in mice and humans, including heart rate, coronary architecture, capillary density, and mechanical properties of the myocardium, which limit the extrapolation of studies to clinical therapy. Among larger animal species, dogs, pigs, and sheep are useful models. Echocardiography and cardiac magnetic resonance imaging techniques used in humans can be applied to these species. Improvement of cardiac function was reported in rabbits, dogs, sheep, and pigs by using a variety of cells, including skeletal myoblasts, bone marrow- and adipose tissue-derived stem cells, cardiac stem cells, and endothelial adult stem cells [45-47]. A recent meta-analysis of the 52 published preclinical studies involving large animals that received cardiac stem cells as therapy for ischemic heart disease concluded that these models can predict the outcome of clinical trials and that treatments are safe [48]. These studies potentially can address a variety of important issues before clinical trials can be conducted, including determining the optimal cell type and delivery method, time of administration, and type of clinical condition for which a treatment can be beneficial. It should be noted that the study concluded that the cell treatment led to improvement in left ventricular ejection fraction but did not prevent ventrical remodeling, at least for over the short term of about 4 months. Also, significant heterogeneity and inconsistency among data sets were observed. Variability of the results was not correlated with the type of cells used, species of animals, or model of infarction. Higher cell numbers, late injections, use of MSCs, and therapy aimed at the ischemic/reperfusion myocardial infarction model show the most beneficial effects in comparison with other treatment regimens and the application of bone marrow mononuclear cells and chronic infarct model. Most importantly, results of preclinical studies in large animals clearly showed that repeated intramyocardial injections of high doses of MSCs were safe and had no adverse effects [49,50]. The studies suggested strategies to obtain a sustained effect, including optimizing the number of cells, time of delivery, and cell type. Reports using mouse MSCs have raised concerns about tumor formation, whereas none of the large animal studies displayed these problems. Future studies should continue safety experiments for longer time periods and should focus on improving established protocols to increase treatment efficacy. Other types of stem cell should also be tested.

\section{Conclusions}

Current progress in stem cell biology and the results of preclinical investigations of stem cell-based therapy 
provide new prospects for regenerative medicine. Animal models offer the 'whole organism' environment for testing feasibility, safety, and efficacy of this new class of therapeutics. Most of the information regarding stem cell behavior and the potential to mitigate disease has been obtained using mice. For a variety of disease conditions, these models have significant limitations that can potentially be overcome by the complementary use of large animal models for preclinical validation. The creation of a more informative set of animal models for stem cell-based therapies will require solving several problems.

1. There is a paucity of well-characterized stem cell lines from larger animals and protocols for their manipulation and characterization. In parallel, there is a lack of centralized resources to characterize and perform quality control of standardized cells and distribute them to investigators. There are very limited data regarding the similarity of large animal stem cells to human cells. Therefore, comparative studies are of primary importance.

2. Low levels of cell engraftment and low efficiency of differentiation are significant limitations for practical applications of stem cells. New approaches should be developed to increase retention of transplanted cells in the host. Techniques to monitor cell behavior in vivo should be further developed in order to elucidate the precise mechanism of stem cell action and to monitor properties in animal models.

3. The absence of models for disease conditions precisely recapitulating the human phenotype with comparable organ sizes and physiologies can be a significant limitation. Careful and rigorous selection of the best animal models for specific diseases is critical. The cost, availability of animals and genetic tools, and appropriate infrastructure are important factors when choosing the optimal model. Concerted breeding efforts might provide the most economical approach in this regard. Large animal models will present new opportunities to study chronic diseases with complex genetic and environment interactions.

4. Young, healthy animals are usually used in stem cellbased experiments, whereas the human population is very complex, with ill patients of various ages. Conditions may have been already treated with drugs and other interventions. Owing to cost, sample sizes for large animal studies must often be minimized, potentially leading to underpowered experiments. Long-term monitoring may also be limited by the cost of maintaining animals. Variability among individuals, common in large, outbred animal species, must also be considered. Significant statistical considerations in the plan for large animal studies include research design that requires blinded experiments, randomization, and dose escalation studies.
5. There have been some successes in making transgenic animals, although technologies are not nearly as well developed for large animals as they are for mice. Humanized animal models, particularly mice, have reached significant milestones, including allowing the reconstruction of human hematopoiesis and immunity and recapitulating some human disease conditions. An important step will be the creation and use of humanized large animal models such as pigs and nonhuman primates, which will complement mice and may have greater predictive capability.

6. The discussion of the use of animals as model systems will not be complete without serious attention to regulatory and ethical issues. There is a need for further development of the regulatory requirements for large animal studies to ensure efficacy and safety of stem cell-based product applications for human therapeutics. The use of large animals, among which are companion animals as well as non-human primates, raises societal concerns because of their psychosocial awareness and privileged status in the human community. We emphasize that the husbandry of animals, both large and small, is highly regulated and scrutinized by multiple government and non-government entities. Compliance with high standards of care, refinement of research methodology, and husbandry techniques should be seriously considered before planning any experiments with these animals. Additional research is required to understand the distress mechanisms upon cell transplantation, especially in attempts to cure diseases for which these therapeutic approaches have not been previously considered. For certain applications, it still may be more economical to conduct preliminary testing in small animals followed by use of larger animals that are more similar morphologically and physiologically to humans.

This article is part of a thematic series on Clinical applications of stem cells edited by Mahendra Rao. Other articles in the series can be found online at http://stemcellres.com/series/clinical

\section{Abbreviations}

ESC, embryonic stem cell; iPSC, induced pluripotent stem cell; LIF/STAT3, leukemia inhibitory factor/signal transducer and activator of transcription 3; MSC, mesenchymal stem cell; MPTP, 1-methyl-4-phenyl-1,2,3,6tetrahydropyridine; SCNT, somatic cell nuclear transfer.

\section{Competing interests}

The authors declare that they have no competing interests.

\section{Authors' contributions}

All authors contributed to the manuscript and read and approved the final version.

\section{Acknowledgments}

This work was supported by National Institutes of Health grant R01HD069979 (RMR). The views and opinions expressed in this article do not necessarily represent those of the National Institutes of Health. 


\section{Author details}

'Division of Comparative Medicine/ORIP/DPCPSI/OD, National Institutes of Health, 6701 Democracy Blvd, Suite 943/950, Bethesda, MD 20892, USA. ${ }^{2}$ Division of Animal Sciences, University of Missouri, 240b C.S. Bond Life Sciences Center, 1201 East Rollins Street, Columbia, MO 65211, USA.

Published: 28 March 2013

\section{References}

1. Joers VL, Emborg ME: Preclinical assessment of stem cell therapies for neurological diseases. ILAR J 2009, 51:24-41.

2. Navarro R, Juhas S, Keshavarzi S, Juhasova J, Motlik J, Johe K, Marsala S, Scadeng M, Lazar P, Tomori Z, Schulteis G, Beattie M, Ciacci JD, Marsala M: Chronic spinal compression model in minipigs: a systematic behavioral, qualitative, and quantitative neuropathological study. J Neurotrauma 2012, 29:499-513

3. Bull ND, Martin KR: Concise review: toward stem cell-based therapies for retinal neurodegenerative diseases. Stem Cells 2011, 29:1170-1175.

4. Van der Velden J, Snibson KJ: Airway disease: the use of large animal models for drug discovery. Pulm Pharmacol Ther 2011, 24:525-532.

5. Plews JR, Gu M, Longaker MT, Wu JC: Large animal induced pluripotent stem cells as pre-clinical models for studying human disease. J Cell Mol Med 2012, 16:1 196-1202

6. Alstrup AK, Winterdahl M: Imaging technique in large animals. Scand J Lab Anim Sci 2009, 36:55-66.

7. Yang PC: Is reliable in vivo detection of stem cell viability possible in a large animal model of myocardial injury? Circulation 2012, 126:388-390.

8. Telugu BP, Ezashi T, Roberts RM: Porcine induced pluripotent stem cells analogous to naive and primed embryonic stem cells of the mouse. Int J Dev Biol 2010, 54:1703-1711.

9. Vassiliev I, Vassilieva S, Truong KP, Beebe LF, Mcllfatrick SM, Harrison SJ, Nottle $M B$ : Isolation and in vitro characterization of putative porcine embryonic stem cells from cloned embryos treated with trichostatin A. Cell Reprogram 2011, 13:205-213.

10. Matsunari $H$, Nagashima H: Application of genetically modified and cloned pigs in translational research. J Reprod Dev 2009, 55:225-230.

11. Staunstrup NH, Madsen J, Primo MN, Li J, Liu Y, Kragh PM, Li R, Schmidt M, Purup S, Dagnæs-Hansen F, Svensson L, Petersen TK, Callesen H, Bolund L, Mikkelsen JG: Development of transgenic cloned pig models of skin inflammation by DNA transposon-directed ectopic expression of human beta1 and alpha2 integrin. PLoS One 2012, 7:e36658.

12. Rogers CS, Stoltz DA, Meyerholz DK, Ostedgaard LS, Rokhlina T, Taft PJ, Rogan MP, Pezzulo AA, Karp PH, Itani OA, Kabel AC, Wohlford-Lenane CL, Davis G., Hanfland RA, Smith TL, Samuel M, Wax D, Murphy CN, Rieke A, Whitworth K UC A, Starner TD, Brogden KA, Shilyansky J, McCray PB Jr, Zabner J, Prather RS, Welsh MJ: Disruption of the CFTR gene produces a model of cystic fibrosis in newborn pigs. Science 2008, 321:1837-1841.

13. Ross JW, Fernandez de Castro JP, Zhao J, Samuel M, Walters E, Rios C, BrayWard P, Jones BW, Marc RE, Wang W, Zhou L, Noel JM, McCall MA, DeMarco PJ, Prather RS, Kaplan HJ: Generation of an inbred miniature pig model of retinitis pigmentosa. Invest Ophthalmol Vis Sci 2012, 53:501-507.

14. Klymiuk N, Aigner B, Brem G, Wolf E: Genetic modification of pigs as organ donors for xenotransplantation. Mol Reprod Dev 2010, 77:209-221.

15. Ezashi $T$, Telugu BP, Roberts RM: Induced pluripotent stem cells from pigs and other ungulate species: an alternative to embryonic stem cells? Reprod Domest Anim 2012, 47 Suppl 4:92-97.

16. Glover JC, Boulland JL, Halasi G, Kasumacic N: Chimeric animal models in human stem cell biology. ILAR J 2009, 51:62-73.

17. Martinez-Gonzalez I, Moreno R, Petriz J, Gratacos E, Aran JM: Engraftment potential of adipose tissue-derived human mesenchymal stem cells after transplantation in the fetal rabbit. Stem Cells Dev 2012, 21:3270-3277.

18. Fujiki Y, Fukawa K, Kameyama K, Kudo O, Onodera M, Nakamura Y, Yagami K, Shiina Y, Hamada H, Shibuya A, Nakauchi H: Successful multilineage engraftment of human cord blood cells in pigs after in utero transplantation. Transplantation 2003, 75:916-922.

19. Zanjani ED, Pallavicini MG, Ascensao JL, Flake AW, Langlois RG, Reitsma M, MacKintosh FR, Stutes D, Harrison MR, Tavassoli M: Engraftment and long term expression of human fetal hemopoietic stem cells in sheep following transplantation in utero. J Clin Invest 1992, 89:1178-1188.

20. Zeng F, Chen MJ, Huang WY, Yan JB, Xiao YP, Gong ZJ, Ren ZR, Huang SZ: In utero transplantation of human hematopoetic stem cells into fetal goats under B-type ultrasonographic scan: an experimental model for the study of potential prenatal therapy. Eur J Obstet Gynecol Reprod Biol 2005,

118:170-173.

21. Harrison MR, Slotnick RN, Crombleholme TM, Golbus MS, Tarantal AF, Zanjani ED: In-utero transplantation of fetal liver haemopoietic stem cells in monkeys. Lancet 1989, 2:1425-1427.

22. Michel-Monigadon D, Brachet P, Neveu I, Naveilhan P: Immunoregulatory properties of neural stem cells. Immunotherapy 2011, 3:39-41.

23. Le Bas-Bernardet S, Tillou X, Poirier N, Dilek N, Chatelais M, Devallière J, Charreau B, Minault D, Hervouet J, Renaudin K, Crossan C, Scobie L, Cowan PJ, d'Apice AJ, Galli C, Cozzi E, Soulillou JP, Vanhove B, Blancho G: Xenotransplantation of galactosyl-transferase knockout, CD55, CD59, CD39, and fucosyl-transferase transgenic pig kidneys into baboons. Transplant Proc 2011, 43:3426-3430.

24. Zhao T, Zhang ZN, Rong Z, Xu Y: Immunogenicity of induced pluripotent stem cells. Nature 2011, 474:212-215.

25. Poncelet AJ, Vercruysse J, Saliez A, Gianello P: Although pig allogeneic mesenchymal stem cells are not immunogenic in vitro, intracardiac injection elicits an immune response in vivo. Transplantation 2007. 83:783-790.

26. Beggs KJ, Lyubimov A, Borneman JN, Bartholomew A, Moseley A, Dodds R, Archambault MP, Smith AK, McIntosh KR: Immunologic consequences of multiple, high-dose administration of allogeneic mesenchymal stem cells to baboons. Cell Transplant 2006, 15:711-721.

27. Di Nicola M, Carlo-Stella C, Magni M, Milanesi M, Longoni PD, Matteucci P, Grisanti S, Gianni AM: Human bone marrow stromal cells suppress T-lymphocyte proliferation induced by cellular or nonspecific mitogenic stimuli. Blood 2002, 99:3838-3843.

28. Li J, Ezzelarab MB, Cooper DK: Do mesenchymal stem cells function across species barriers? Relevance for xenotransplantation. Xenotransplantation 2012, 19:273-285

29. Lin CS, Lin G, Lue TF: Allogeneic and xenogeneic transplantation of adipose-derived stem cells in immunocompetent recipients without immunosuppressants. Stem Cells Dev 2012, 21:2770-2778.

30. Gomes JA, Geraldes Monteiro B, Melo GB, Smith RL, Cavenaghi Pereira da Silva M, Lizier NF, Kerkis A, Cerruti H, Kerkis I: Corneal reconstruction with tissue-engineered cell sheets composed of human immature dental pulp stem cells. Invest Ophthalmol Vis Sci 2010, 51:1408-1414.

31. Zhou L, Wang W, Liu Y, Fernandez de Castro J, Ezashi T, Telugu BP, Roberts RM, Kaplan HJ, Dean DC: Differentiation of induced pluripotent stem cells of swine into rod photoreceptors and their integration into the retina. Stem Cells 2011, 29:972-980.

32. Emborg ME, Joers V, Fisher R, Brunner K, Carter V, Ross C, Raghavan R, Brady M, Raschke J, Kubota K, Alexander A: Intraoperative intracerebral MRIguided navigation for accurate targeting in nonhuman primates. Cell Transplant 2010, 19:1587-1597.

33. Takahashi J, Takagi Y, Saiki H: Transplantation of embryonic stem cellderived dopaminergic neurons in MPTP-treated monkeys. Methods Mol Biol 2009, 482:199-212.

34. Redmond DE Jr., Bjugstad KB, Teng YD, Ourednik V, Ourednik J, Wakeman DR, Parsons XH, Gonzalez R, Blanchard BC, Kim SU, Gu Z, Lipton SA, Markakis EA, Roth RH, Elsworth JD, Sladek JR Jr., Sidman RL, Snyder EY: Behavioral improvement in a primate Parkinson's model is associated with multiple homeostatic effects of human neural stem cells. Proc Natl Acad SciU S A 2007 104:12175-12180.

35. Bjugstad KB, Redmond DE Jr., Teng YD, Elsworth JD, Roth RH, Blanchard BC, Snyder EY, Sladek JR Jr: Neural stem cells implanted into MPTP-treated monkeys increase the size of endogenous tyrosine hydroxylase-positive cells found in the striatum: a return to control measures. Cell Transplant 2005, 14:183-192.

36. Emborg ME, Ebert AD, Moirano J, Peng S, Suzuki M, Capowski E, Joers V, Roitberg BZ, Aebischer P, Svendsen CN: GDNF-secreting human neural progenitor cells increase tyrosine hydroxylase and VMAT2 expression in MPTP-treated cynomolgus monkeys. Cell Transplant 2008, 17:383-395.

37. Takagi Y, Takahashi J, Saiki H, Morizane A, Hayashi T, Kishi Y, Fukuda H, Okamoto Y, Koyanagi M, Ideguchi M, Hayashi H, Imazato T, Kawasaki H, Suemori H, Omachi S, lida H, Itoh N, Nakatsuji N, Sasai Y, Hashimoto N: Dopaminergic neurons generated from monkey embryonic stem cells function in a Parkinson primate model. J Clin Invest 2005, 115:102-109.

38. Kriks S, Shim JW, Piao J, Ganat YM, Wakeman DR, Xie Z, Carrillo-Reid L, Auyeung G, Antonacci C, Buch A, Yang L, Beal MF, Surmeier DJ, Kordower JH, 
Tabar V, Studer L: Dopamine neurons derived from human ES cells efficiently engraft in animal models of Parkinson's disease. Nature 2011, 480:547-551.

39. Daadi MM, Grueter BA, Malenka RC, Redmond DE Jr., Steinberg GK: Dopaminergic neurons from midbrain-specified human embryonic stem cell-derived neural stem cells engrafted in a monkey model of Parkinson's disease. PLoS One 2012, 7:e41120.

40. Redmond DE Jr., Weiss S, Elsworth JD, Roth RH, Wakeman DR, Bjugstad KB, Collier TJ, Blanchard BC, Teng YD, Synder EY, Sladek JR Jr.: Cellular repair in the parkinsonian nonhuman primate brain. Rejuvenation Res 2010, 13:188-194.

41. Sasaki M, Honmou O, Radtke C, Kocsis JD: Development of a middle cerebral artery occlusion model in the nonhuman primate and a safety study of i.v. infusion of human mesenchymal stem cells. PLoS One 2011, 6:e26577.

42. Guercio A, Di Marco P, Casella S, Cannella V, Russotto L, Purpari G, Di Bella S, Piccione G: Production of canine mesenchymal stem cells from adipose tissue and their application in dogs with chronic osteoarthritis of the humeroradial joints. Cell Biol Int 2012, 36:189-194.

43. Chu CR, Szczodry M, Bruno S: Animal models for cartilage regeneration and repair. Tissue Eng Part B Rev 2010, 16:105-115.

44. Vieira NM, Valadares M, Zucconi E, Secco M, Bueno Junior CR, Brandalise V, Assoni A, Gomes J, Landini V, Andrade T, Caetano HV, Vainzof M, Zatz M: Human Adipose-Derived Mesenchymal Stromal cells injected systemically into GRMD dogs without immunosuppression are able to reach the host muscle and express human dystrophin. Cell Transplant 2012, 21:1407-1417.
45. Gandolf F, Vanelli A, Pennarossa G, Rahaman M, Acocella F, Brevini TA: Large animal models for cardiac stem cell therapies. Theriogenology 2011, 75:1416-1425

46. Amado LC, Schuleri KH, Saliaris AP, Boyle AJ, Helm R, Oskouei B, Centola M, Eneboe V, Young R, Lima JA, Lardo AC, Heldman AW, Hare JM: Multimodality noninvasive imaging demonstrates in vivo cardiac regeneration after mesenchymal stem cell therapy. J Am Coll Cardiol 2006, 48:2116-2124.

47. Mazhari R, Hare JM: Translational findings from cardiovascular stem cell research. Trends Cardiovasc Med 2012, 22:1-6.

48. van der Spoel TI, Jansen of Lorkeers SJ, Agostoni P, van Belle E, Gyongyosi M, Sluijter JP, Cramer MJ, Doevendans PA, Chamuleau SA: Human relevance of pre-clinical studies in stem cell therapy: systematic review and metaanalysis of large animal models of ischaemic heart disease. Cardiovasc Res 2011, 91:649-658.

49. Kraitchman DL, Heldman AW, Atalar E, Amado LC, Martin BJ, Pittenger MF, Hare JM, Bulte JW: In vivo magnetic resonance imaging of mesenchymal stem cells in myocardial infarction. Circulation 2003, 107:2290-2293.

50. Poh KK, Sperry E, Young RG, Freyman T, Barringhaus KG, Thompson CA: Repeated direct endomyocardial transplantation of allogeneic mesenchymal stem cells: safety of a high dose, 'off-the-shelf', cellular cardiomyoplasty strategy. Int J Cardio/ 2007, 117:360-364.

doi:10.1186/scrt171

Cite this article as: Harding J, et al:: Large animal models for stem cell therapy. Stem Cell Research \& Therapy 2013, 4:23. 